\title{
AGE OF CRARY ICE RISE, ANTARCTICA, DETERMINED FROM TEMPERATURE-DEPTH PROFILES
}

by

Robert A. Bindschadler,

(Code 671, NASA/Goddard Space Flight Center, Greenbelt, MD 20771, U.S.A.)

Eric P. Roberts*

(Department of Civil Engineering, University of Maryland, College Park, MD 20740, U.S.A.)

and

Almut Iken

(Gloriastrasse 37/39, VAW/ETH-Zentrum, Zürich, Switzerland)

\begin{abstract}
Temperature-depth measurements from two sites on Crary Ice Rise, Antarctica are analyzed to deduce the time the ice first grounded at each location. At the thicker site $(480 \mathrm{~m})$, the best estimate of the time since grounding is 1100 years. At the shallower site $(369 \mathrm{~m})$ the grounding is more recent, 580 years ago, and there is evidence that basal cooling was delayed for 450 years while water at the base was freezing. This analysis leads to the conclusion that Crary Ice Rise was formed by at least two separate grounding events and is not a remnant of a more extensive grounded ice sheet which occupied the present position of the Ross Ice Shelf.
\end{abstract}

\section{INTRODUCTION}

At present the West Antarctic ice sheet is only two-thirds of its size attained during the last glacial maximum 18000 years B.P. (Denton and Hughes, 1981). Recent field measurements reveal dramatic changes taking place, especially in the vicinity of Crary Ice Rise (Stephenson and Bindschadler, 1988; Bindschadler and others, in press); however, it is yet unclear whether these changes represent a prolonged retreat from the last maximum, an advance in response to some other climatic forcing, or internal adjustment of the ice sheet. To understand the present behavior of the ice sheet and predict its future, a chronology of events associated with the current changes in size and shape of the ice sheet must be ascertained.

Crary Ice Rise is important in establishing such a chronology because it is the largest ice rise on the Ross Ice Shelf and lies directly in the path of ice discharged from Ice Stream B. Is this ice rise a remnant of a larger, but now diminished, ice sheet or was all the grounded ice in the Ross Sea basin removed by a more complete retreat and Crary Ice Rise formed only recently by increased discharge of Ice Stream B?

We answer this question by using a proven technique for deducing the time since an ice shelf grounded based on analyzing temperature-depth measurements. We estimate these dates at two locations on Crary Ice Rise and discuss the implications of our results in the context of the changing West Antarctic ice sheet.

\section{METHOD}

The method used to date the ice rise was developed and first applied by Lyons and others (1972) on the Ward

*Present address: Groundwater Technology Inc., 10610 Iron Bridge Road, Jessup, MD 20794, U.S.A.
Hunt Ice Shelf, Canada. It draws on the fact that the basal temperatures of thermally equilibrated floating ice and grounded ice are very different. The basal temperature of an ice shelf is fixed at the freezing point of the adjacent seawater, while for a grounded ice rise the basal temperature is determined by the rate of heat conduction from the underlying rock toward the surface. When the ice shelf grounds on a marine bed, the basal heat source switches from sub-shelf water to geothermal heat, forcing a transient shift in the temperature structure of the ice. This shift begins with rapid changes in the lowest layers of the ice which diminish with time. The temperature structure is altered throughout the ice thickness by an exponential approach to the equilibrated condition for grounded ice.

The success of the dating method rests on being able to model this transient response numerically. Beginning with a known ice-shelf temperature profile at the moment of grounding, a series of temperature profiles for later times can be calculated. By comparing a measured temperature profile with the predicted profiles, the best match provides an estimate of time since grounding.

We have developed a transient temperature model similar to the one described in MacAyeal and Thomas (1980). The principal difference is in the method of solution: we use finite difference techniques while MacAyeal and Thomas used a finite-element model. Both models account for vertical flow of heat, vertical variations of thermal properties of the ice, and include thermal inertia of the bed by calculating the changing temperature profile in the bed as well as the ice.

In the calculation of a steady-state ice-shelf temperature profile, the surface accumulation rate and basal melt or freeze rate balance the depth-constant vertical strain-rate to guarantee a time-invariant ice thickness. For the transient grounded condition, a geothermal heat flux is specified and the vertical strain-rate varies linearly with depth from zero at the base to a specified maximum at the surface. In both cases, horizontal temperature gradients are assumed small and horizontal advection is neglected. Depending on the values of vertical strain-rate and accumulation rate, the grounded ice may thicken, thin or remain constant. For both the ice-shelf and grounded cases, a mean annual surface temperature is applied and the conductivity and diffusivity of the firn vary according to the density profile measured in the $\mathrm{J} 9$ core hole using equations empirically fit by MacAyeal (personal communication) to thermal data collected by Weller and Schwerdtfeger (1970).

\section{DATA}

Holes to the subglacial bed were drilled at two sites on Crary Ice Rise during the 1987-88 field season by 


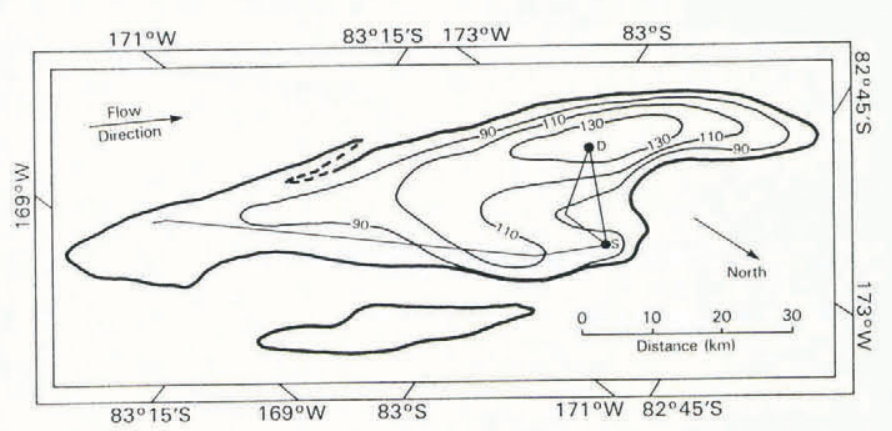

Fig. 1. Surface topography of Crary Ice Rise with locations of deep and shallow drill sites indicated by D and S, respectively. Straight lines on ice rise are lines leveled by optical survey. Contour lines are of elevation (in $\mathrm{m}$ ) above mean sea-level.

hot-water drills designed and operated by the Polar Ice Coring Office (Koci and Bindschadler, 1989) (Fig. 1). Cables with installed thermistors were suspended in each hole and allowed to freeze into the ice. The deeper hole, Site D $(480 \mathrm{~m})$, was made on the crest of a longitudinal ridge, the highest and most prominant feature of the ice rise. From radar sounding data provided by Blankenship (personal communication), the bed underneath this ridge dips to the southwest (orthogonal to the strike of the ridge) at a slope of 0.01 .

The shallower hole, Site S $(369 \mathrm{~m})$, was drilled $15 \mathrm{~km}$ northeast of Site D, near the summit of a local knoll on the ice rise (see Fig. 1). This location coincided with the site of the highest known subglacial elevation $(275 \mathrm{~m}$ below sea-level) based on available radar soundings (personal communication from S. Shabtaie). This bed elevation is $60 \mathrm{~m}$ higher than the bed elevation at Site D. Thus it was expected that Site $S$ would be where the ice rise had grounded first and be oldest. Measurements of the initial cooling in this hole were misinterpreted by Bindschadler and others (1989) as indicating a temperate bed. Here the equilibrated temperatures, measured at each site during the 1988-89 field season, are analyzed.

In addition to the temperature measurements, surface horizontal strain-rates were measured at Site S. The pattern of snow accumulation was measured along three lines of surface poles between the two drill sites and a third location further upstream (see Fig. 1). These data were useful in setting some of the parameters of the temperature model. Most of the model parameters have a narrow range of values based on our own data collected in the vicinity of Crary Ice Rise (Bindschadler and others, 1988) and data from Thomas and others (1984).

\section{ANALYSIS}

For each run of the model, an initial steady-state iceshelf temperature profile was calculated from the specified surface and base temperatures, accumulation rate, vertical strain-rate, basal melt/freeze rate, firn-density profile, and ice thickness. The surface temperature was taken from the measured temperatures, the basal temperature was fixed at $-2{ }^{\circ} \mathrm{C}$, the accumulation rate, basal melt/freeze rate and vertical strain-rate had to balance, the firn density corresponded to the $\mathrm{J} 9$ profile, and the ice thickness was set equal to that value required for the floating ice to make initial contact with the known elevation of the bed.

Beginning with this temperature profile, the model calculated the transient temperature profiles for the grounded ice. These calculations required that the geothermal heat flux and conductivity and diffusivity of the bed also be specified. At both sites a heat flux value of $0.077 \mathrm{~W} \mathrm{~m}^{-2}$ was used. Similar values have been calculated by others for other regions in West Antarctica (Gow, 1968; Thomas and others, 1980; Alley and Bentley, 1988).

Based on the composition of an igneous rock fragment removed from the hole at Site D (Koci and Bindschadler, 1989), the bed was assumed to be a rhyolite with a conductivity of $2.3 \mathrm{~W} \mathrm{~m}^{-1} \mathrm{deg}^{-1}$ and a diffusivity of $44.15 \mathrm{~m}^{2} \mathrm{a}^{-1}$ (Sabins, 1987). These thermal parameters of the bed were assumed to be constant with both depth and teriperature.

To determine the best match between the measured temperatures and the predictions, the standard error $(E)$ between the measurements and predictions was calculated every 20 years by the formula,

$$
E=\left\{\sum_{i=1}^{n}\left(T_{\mathrm{m}_{i}}-T_{\mathrm{p}_{i}}\right)^{2} /(n-2)\right\}^{\frac{1}{2}}
$$

where $T_{\mathrm{m}}$ and $T_{\mathrm{p}}$ are the measured and predicted temperatures, $n$ is the number of data points. The minimum value of $E$ provides the best estimate of age for that set of model parameters. The magnitude of the error for different parameter values provides an indication of the optimization of each parameter set.

Figure 2 presents the results of our best simulation of the transient condition at Site D. The minimum value of

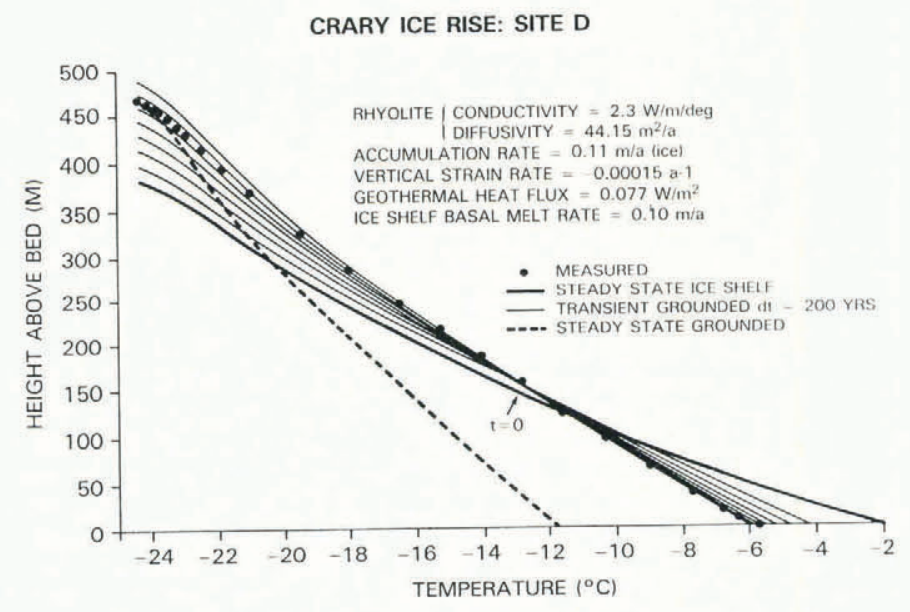

Fig. 2. Measured and predicted temperature profiles at Site D. Steady-state profile for grounded ice uses the current ice thickness and modeled accumulation rate. See text for numeric values of these and other model parameters.

the error is $0.08^{\circ} \mathrm{C}$ and occurs at 1100 years. The particular parameters used for this calculation are: accumulation rate $0.11 \mathrm{~m} \mathrm{a}^{-1}$ (ice equivalent), surface vertical strain-rate $0.00015 \mathrm{a}^{-1}$, and an ice-shelf basal melt rate of $0.10 \mathrm{~m} \mathrm{a}^{-1}$. The figure shows the initial steady-state ice-shelf temperature profile as well as the transient profiles every 200 years for 1400 years. It also includes the steady-state temperature profile for grounded ice at the assumed accumulation rate and current ice thickness. It is clear from this figure that the rate of basal cooling decreases with time but the transient profiles, even after 1400 years, are far from steady-state.

An extensive sensitivity study was conducted for this profile. Each parameter was varied within reasonable limits to gauge the variation in the magnitude of the minimum error and the sensitivity of the age to these changes. Surface accumulation rate was identified as the most sensitive parameter to dating the ice rise at this site by this method. Figure 3 establishes the nature of this sensitivity by presenting the various choices of accumulation rate studied, how the minimum error varied, and the age which corresponded to each accumulation rate.

We assume that the specified model parameters do not change in time. From the sensitivity study this assumption appears to have little effect on estimating the time since grounding for any parameter except accumulation rate. From the distribution of accumulation rates measured on and around the ice rise (Thomas and others, 1984), it appears that the ice rise receives less accumulation than the surrounding ice shelf. Based on these data, we feel the best estimate of accumulation rate at Site $\mathrm{D}$ is $0.11 \mathrm{~m} \mathrm{a}^{-1}$ (ice equivalent) and attach a $0.015 \mathrm{~m} \mathrm{a}^{-1}$ estimate of the error (one sigma). Using Figure 3 , this translates into a range of uncertainty of the time since grounding of from 950 to 1340 years with a preferred value of 1100 years ago. 


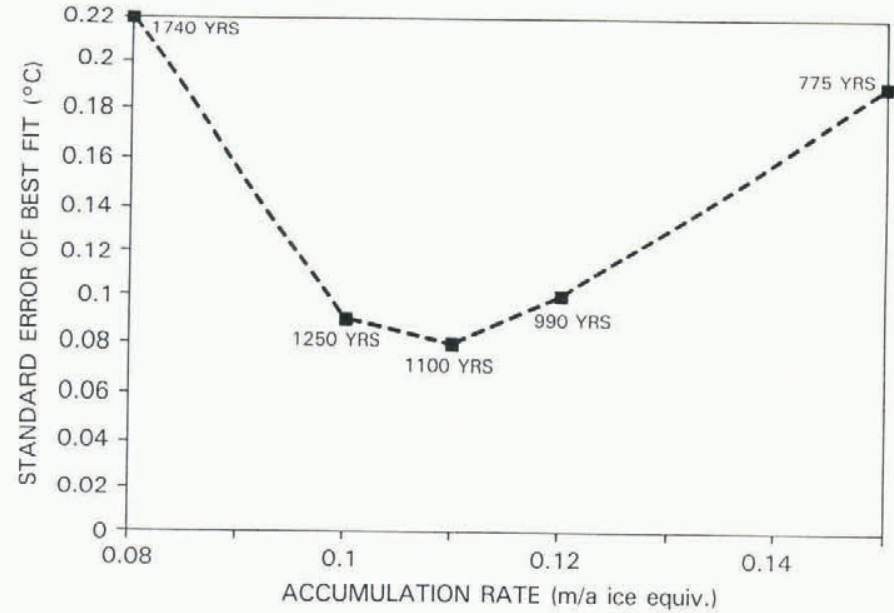

Fig. 3. Dependence of minimum standard error (Equation (1)) and time since grounding on surface accumulation rate for Site D.

When the same approach is applied to the temperature profile at Site S, there is no possibility of matching the data using reasonable parameter values. The principal difficulty is that the basal temperature cools so rapidly that the ice thickness has insufficient time to reach the current thickness. Either an unreasonably high geothermal heat flux, in excess of $0.10 \mathrm{~W} \mathrm{~m}^{-2}$, or an unrealistically high thickening rate of $0.5 \mathrm{~m} \mathrm{a}^{-1}$ is necessary to match the profile simultaneously at the upper and lower surfaces. Even then the remainder of the measured profile is poorly matched and $E$ is large.

This discovery leads us to consider that there may have been a period of time after grounding during which the ice rise at Site $S$ began to thicken but the base had not yet begun to cool because water trapped in subglacial material was being frozen. The clastic material in a clay-like matrix recovered from the bed at Site $D$ suggests that after grounding there may have been residual water in the subglacial material. The early stages of grounding could have also permitted the seepage of water under the ice by tidal action. The hypothesis of trapped basal water allows us to achieve a satisfactory match between the predicted and measured profiles using reasonable model parameters. The optimal match, with $E=0.13^{\circ} \mathrm{C}$, occurs for an age of 580 years (450 years of freezing water at the base and 130 years during which basal cooling took place). From the thermal gradients present in the ice and bed, the amount of water refrozen during the 450 years would have been equal to a layer $3.7 \mathrm{~m}$ thick. This simulation, shown in Figure 4 uses the same parameters as at Site D with the exception of accumulation rate $\left(0.15 \mathrm{~m} \mathrm{a}^{-1}\right)$ and vertical strain-rate $\left(-0.0004 \mathrm{a}^{-1}\right)$. These two differences lead to an average thickening rate $7 \%$ higher than at Site D.

The attainment of a good match for Site D without needing to invoke a similar period of freezing of basal water is in large part due to the additional time basal cooling has been taking place at that site. Any delay will be most apparent immediately after all the basal water has frozen because the basal temperature will still be at $-2{ }^{\circ} \mathrm{C}$ while the thickening will have already taken place for some time. From Figure 2 it can be seen that at Site D basal cooling has slowed considerably from the rapid changes that occurred in the first 200 years. Thus, while a similar process may have taken place at Site D, it happened too long ago to accurately infer the duration of such a delay from our data. It does, however, add an uncertainty to our upper bound of the age of that part of the ice rise.

\section{CONCLUSIONS}

There are three major conclusions to be drawn from this analysis. The first is the large difference in age for two sites on the same ice rise separated by only $15 \mathrm{~km}$. From the shape of the ice rise (see Fig. 1), it is not likely that the ice rise has experienced a gradual lateral growth.
CRARY ICE RISE: SITE S

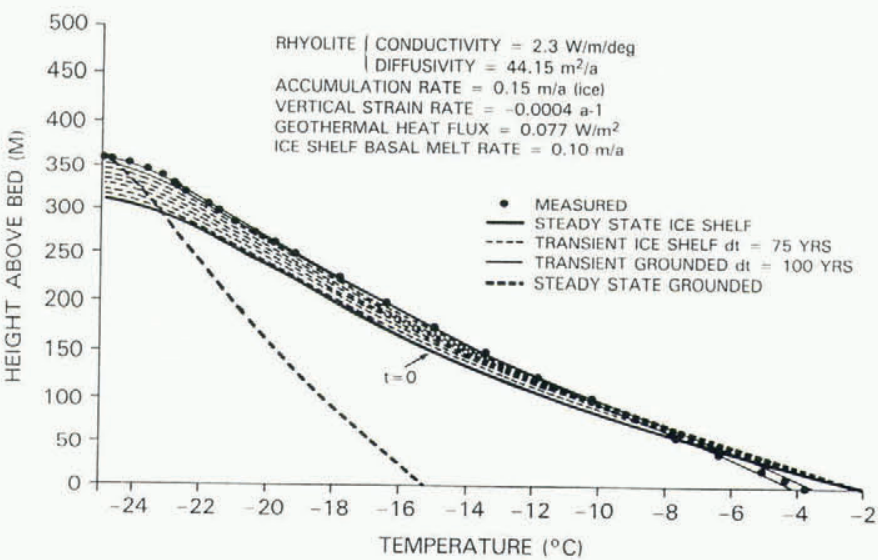

Fig. 4. Measured and predicted temperature profiles at Site S. Steady-state profile for grounded ice uses the current ice thickness and modeled accumulation rate. See text for numeric values of these and other model parameters.

There is thinner ice between the ridge on which the deeper hole was drilled, and the knoll near whose summit the shallow hole was placed. This topography suggests that the ice rise was present along the ridge for the last 1100 years, perhaps extending downstream some distance, and that more recent grounding in the vicinity of the shallow hole ensued about 600 years ago. The present-day Crary Ice Rise represents the coalescence of at least two separate grounding events. Neither event appears to coincide with the cessation of fast flow on Ice Stream C, estimated by Shabtaie and Bentley (1987) as happening 200 years ago. Another candidate event is an even earlier circumstance on Ice Stream $C$ when the width at the grounding line narrowed considerably (Stephenson and Bindschadler, this volume).

It is also significant that the highest part of Crary Ice Rise is probably not much older than 1100 years. With extensive radar sounding data already covering most of the ice rise, it is likely that no ice on the rise is thicker. Thus, Crary Ice Rise is not a climatic remnant of the last glacial maximum. Its creation most likely was the result of a thickening event possibly caused by the current depletion of the catchment of Ice Stream B (Shabtaie and others, 1988; Whillans and Bindschadler, 1988).

Finally, we conclude that basal freezing of water under grounded ice does occur and that this effect delays the cooling of the basal ice. The conditions under which this effect occurs are not revealed by this analysis but we must warn those that use this dating technique that the possibility exists and it affects the calculated age of ice rises.

\section{ACKNOWLEDGEMENTS}

We thank C. Lingle, S. Stephenson, P. Vornberger, and J. Zwally for their helpful comments on this paper. Also excellent reviews were provided by D. MacAyeal and two anonymous persons. This research was supported by grant DPP-8614407 from the U.S. National Science Foundation.

\section{REFERENCES}

Alley, R.B. and C.R. Bentley. 1988. Ice-core analysis on the Siple Coast of West Antarctica. Ann. Glaciol., 11, 1-7.

Bindschadler, R.A., S.N. Stephenson, E.P. Roberts, D.R. MacAyeal, and D.R. Lindstrom. 1988. Data report for the Siple Coast Project. Washington, DC, National Aeronautics and Space Administration. (NASA Technical Memorandum 100708.)

Bindschadler, R.A., B. Koci, S. Shabtaie, and E. Roberts. 1989. Evolution of Crary Ice Rise, Antarctica. (Abstract.) Ann. Glaciol., 12, 199-200.

Bindschadler, R.A., E.P. Roberts, and D.R. MacAyeal. In press. Distribution of net mass balance in the vicinity of Crary Ice Rise, Antarctica. J. Glaciol. 
Denton, G.H. and T.J. Hughes, eds. 1981. The last great ice sheets. New York, etc., John Wiley and Sons.

Gow, A.J. 1968. Deep core studies of the accumulation and densification of snow at Byrd Station and Little America V, Antarctica. CRREL Res. Rep. 197.

Koci, B, and R.A. Bindschadler. 1989. Hot-water drilling on Crary Ice Rise, Antarctica. (Abstract.) Ann. Glaciol., 12, 214.

Lyons, J.B., R.H. Ragle, and A.J. Tamburi. 1972. Growth and grounding of the Ellesmere Island ice rises. $J$. Glaciol., 11(61), 43-52.

MacAyeal, D.R. and R. H. Thomas. 1980. Ice-shelf grounding: ice and bedrock temperature changes. $J$. Glaciol., 25(93), 397-400.

Sabins, F.F. 1986. Remote sensing, principles and interpretation. New York, W.H. Freeman and Co.

Shabtaie, S. and C.R. Bentley. 1987. West Antarctic ice streams draining into the Ross Ice Shelf: configuration and mass balance. J. Geophys. Res., 92(B2), 1311-1336.
Shabtaie, S., C.R. Bentley, R.A. Bindschadler, and D.R. MacAyeal. 1988. Mass-balance studies of ice streams A, $\mathrm{B}$, and $\mathrm{C}$, West Antarctica, and possible surging behavior of Ice Stream B. Ann. Glaciol., 11, 137-149.

Stephenson, S.N. and R.A. Bindschadler. 1990. Does satellite imagery reveal ice stream evolution? Ann. Glaciol., 14, 273-277.

Thomas, R.H., D.R. MacAyeal, C.R. Bentley, and J.L. Clapp. 1980. The creep of ice, geothermal heat flow, and Roosevelt Island, Antarctica. J. Glaciol., 25(91), 47-60.

Thomas, R.H., D.R. MacAyeal, D.H. Eilers, and D.R. Gaylord. 1984. Glaciological studies on the Ross Ice Shelf, Antarctica, 1973-1978. Antarct. Res. Ser., 42, 21-53.

Weller, G. and P. Schwerdtfeger. 1970. Thermal properties and heat transfer processes of the snow of the central Antarctic plateau. International Association of Scientific Hydrology Publication 86 (ISAGE), 284-298.

Whillans, I.M. and R.A. Bindschadler. 1988. Mass balance of Ice Stream B, West Antarctica. Ann. Glaciol., 11, 187-193. 